\title{
Inhibition of mammalian target of rapamycin improves neurobehavioral deficit and modulates immune response after intracerebral hemorrhage in rat
}

Qin Lu ${ }^{1,2}$, Lu Gao ${ }^{1,2}$, Lijie Huang 1,2, Linhui Ruan ${ }^{1,2}$, Jianjing Yang ${ }^{1,2}$, Weilong Huang ${ }^{1,2}$, Zhenxing Li, ${ }^{1,2}$, Yongliang Zhang ${ }^{1}$, Kunlin $\mathrm{Jin}^{3}$ and Qichuan Zhuge ${ }^{1,2^{*}}$

\begin{abstract}
Background: Mammalian target of rapamycin (mTOR), a serine/threonine kinase, regulates many processes, including cell growth and the immune response. mTOR is also dysregulated in several neurological diseases, such as traumatic brain injury (TBI), stroke, and neurodegenerative disease. However, the role of mTOR in intracerebral hemorrhage $(\mathrm{ICH})$ remains unexplored. The aims of our study were to determine whether inhibiting mTOR signaling could affect the outcome after $\mathrm{ICH}$ and to investigate the possible underlying mechanism.

Methods: A rat ICH model was induced by intracerebral injection of collagenase IV into the striatum, and mTOR activation was inhibited by administration of rapamycin. mTOR signaling activation was determined by western blotting. Neurobehavioral deficit after ICH was determined by a set of modified Neurological Severity Scores (mNSS). The levels of CD4+CD25+Foxp3+ regulatory T cells (Tregs) and cytokines were examined using flow cytometry and ELISA, respectively.
\end{abstract}

Results: Our results demonstrated thatmTOR signaling was activated 30 minutes and returned to its basal level 1 day after ICH. Increased p-mTOR, which mean that mTOR signaling was activated, was predominantly located around the hematoma. Rapamycin treatment significantly improved the neurobehavioral deficit after $\mathrm{ICH}$, increased the number of Tregs, increased levels of interleukin-10 and transforming growth factor- $\beta$ and reduced interferon- $\gamma$ both in peripheral blood and brain.

Conclusions: Our study suggests that mTOR improves ICH outcome and modulates immune response after ICH.

Keywords: ICH, mTOR, Rapamycin, Outcome, Immune response

\section{Introduction}

Stroke is the second leading cause of death worldwide [1], and is one of the major causes of morbidity and mortality. Intracerebral hemorrhage ( $\mathrm{ICH})$, a lethal type of stroke, accounts for $20 \%$ of all strokes [2], and occurs in about $50-60 \%$ of East Asians [3]. Currently, no specific therapies are available that improve the outcome after ICH. Surgical treatment of $\mathrm{ICH}$, such as surgical

\footnotetext{
* Correspondence: zhugeqichuan@vip.163.com

${ }^{1}$ Department of Neurosurgery, First Affiliated Hospital of Wenzhou Medical

University, Wenzhou, Zhejiang, China

${ }^{2}$ Zhejiang Provincial Key Laboratory of Aging and Neurological Disease,

Wenzhou Medical University, Wenzhou, Zhejiang, China

Full list of author information is available at the end of the article
}

removal of the hematoma, is primarily supportive, but the clinical outcome is poor, increasing the potential extensive burden for the family and society. Thus, the problem of improving neurological disability after $\mathrm{ICH}$ is still needs to be resolved.

In the early 1990s, the two yeast genes TOR1 and TOR2 were discovered in the budding yeast Saccharomyces cerevisiae by a group performing genetic screens for the toxic effects of rapamycin [4]. Mammalian target of rapamycin (mTOR) was then quickly identified, purified, and cloned $[5,6]$. mTOR is an evolutionarily conserved serine/ threonine kinase that plays a key role in the regulation of cell growth and metabolism [7]. The mTOR pathway

\section{Biomed Central}

(c) 2014 Lu et al.; licensee BioMed Central Ltd. This is an Open Access article distributed under the terms of the Creative Commons Attribution License (http://creativecommons.org/licenses/by/2.0), which permits unrestricted use, distribution, and reproduction in any medium, provided the original work is properly credited. The Creative Commons Public Domain Dedication waiver (http://creativecommons.org/publicdomain/zero/1.0/) applies to the data made available in this article, unless otherwise stated. 
integrates diverse environmental signals to regulate many processes including autophagy, ribosome biogenesis, transcription, translation, and cytoskeletal organization $[8,9]$. In addition to cancer, dysregulation of mTOR activity has been found in neural diseases, such as epilepsy [10], Parkinson's disease [11,12], Alzheimer's disease [13], and traumatic brain injury (TBI) [14]. Chen et al. found in a model of TBI that mTOR was significantly phosphorylated from 30 minutes to 24 hours after TBI. Considering the role of mTOR in regulating mRNA translation for cell growth, dendritic arborization, and hippocampal synaptic plasticity, its activation may contribute to the deficits in learning and memory after TBI [14]. However, the questions of whether mTOR is also activated after $\mathrm{ICH}$, and whether activation of mTOR related to neurobehavioral deficits still need to be determined.

An increasing number of studies have shown that inflammatory responses are deeply involved in the progression of ICH-induced brain injury $[15,16]$, which may be mediated by: 1) cellular components including local microglia, lymphocytes, and leukocytes, and 2) molecular components including pro-inflammatory and antiinflammatory cytokines. These two major components interact with each other and contribute to the outcome of stroke $[17,18]$. Thymus-derived CD4+CD25+Foxp3+ regulatory $\mathrm{T}$ cells (Tregs) are known to be neuroprotective in stroke [19] by modulating the function of effector $\mathrm{T}$ cells and secreting anti-inflammatory molecules such as interleukin (IL)-10 and transforming growth factor (TGF)- $\beta[20,21]$. Recent studies have shown that mTOR is proving to be a vital link between immune function and metabolism, and inhibition of mTOR by rapamycin promotes the production of CD4+CD25+Foxp3+ Tregs $[22,23]$. Thus, the question arises as to whether inhibition of mTOR might also improve neurological disability by modulating the immune response after $\mathrm{ICH}$.

In order to address the issues described above, we first investigated alterations of the mTOR signaling pathway around the hematoma after $\mathrm{ICH}$, and then examined the effect of rapamycin treatment on neurological deficits after ICH. Finally, we explored the effect of rapamycin administration on immune response in a rat model of $\mathrm{ICH}$.

\section{Materials and methods}

All experimental procedures were approved by the Animal Care Committee of the Wenzhou Medical University.

\section{Animals}

In total, 102 male Sprague-Dawley rats, weighing 280 to $320 \mathrm{~g}$, were randomly divided into eight groups. Group $1(\mathrm{n}=9)$ was the normal control group and did not receive any treatment; group 2 was the ICH group $(n=26)$, which received collagenase injection at 30 minutes, 1 hour, 4 hour, 1 day, and 3 days after induction of stroke; group 3, the AU group $(\mathrm{n}=8)$, received injection of autologous blood; group 4 , the PBS group $(n=6)$, received PBS (containing 2.5\% DMSO, 5\% polyethylene glycol 400 and 5\% Tween 80) 1 hour after $\mathrm{ICH}$; groups 5 to 8 were treated with rapamycin $(\mathrm{n}=53)$ at concentration of 50 $(\mathrm{n}=11), 150(\mathrm{n}=23), 250(\mathrm{n}=11)$, and $500 \mathrm{ug} / \mathrm{kg}(\mathrm{n}=11)$, respectively, via intraperitoneal injection.

\section{$\mathrm{ICH}$ model}

The experimental ICH model was induced by intrastriatal collagenase injection, as previously described by Rosenberg et al. [24]. Briefly, rats were anesthetized using $4 \%$ chloral hydrate and then placed in a stereotaxic frame (KOPF, California, USA) After the bregma was exposed, a borehole $(1 \mathrm{~mm})$ was drilled $3 \mathrm{~mm}$ lateral to the bregma and then a 30-gauge needle was inserted through the bore hole into the striatum $(5 \mathrm{~mm}$ ventral from the skull surface).

For the collagenase-injection model, $1 \mu \mathrm{l}$ collagenase type IV $(0.25 \mathrm{IU} / \mu \mathrm{l})$ was injected into the striatum over a period of 5 minutes to induce $\mathrm{ICH}$. The needle was allowed to remain in situ for another 5 minutes before it was removed.

For the autologous blood-injection model, $50 \mu \mathrm{l}$ autologous blood, which was withdrawn from the caudal artery, was injected into the striatum in a doubleinjection manner, as described previously by Deinsberger et al. [25]. During injection, the temperature was monitored and maintained at $37 \pm 0.5^{\circ} \mathrm{C}$. Animals recovered at room temperature with free access to food and water under a 12-hour light/dark cycle.

\section{Rapamycin}

Rapamycin (Merck Millipore, Darmstadt, Germany) was dissolved in DMSO $(5 \mathrm{mg} / \mathrm{ml})$ and stored at $-20^{\circ} \mathrm{C}$. Before injection, rapamycin was diluted with PBS containing 5\% polyethylene glycol 400 and 5\% Tween 80 . The $\mathrm{ICH}$ rats received a single intraperitoneal injection of rapamycin 1 hour after collagenase administration, and the doses of rapamycin used were 50, 150, 250, and 500 $\mu \mathrm{g} / \mathrm{kg}$ for groups 5 to 8 , respectively.

\section{Western blot analysis}

In order to assess the profile of mTOR activation after $\mathrm{ICH}$, rats were euthanized at 30 minutes, 1 hour, 4 hours, 1 day, 3 days, or 7 days after ICH. The brains were removed, and the left (ipsilateral) and right (contralateral) hemispheres were separated. The tissues were then homogenized in RIPA buffer (Thermo, Rockford, USA) containing $10 \mu \mathrm{l}$ of protease inhibitors and phosphatase inhibitors (Thermo) per $1 \mathrm{ml}$ RIPA. The protein concentration was determined by bicinchoninic acid assay (Thermo). Equivalent quantities of protein $(50 \mu \mathrm{g}$ per lane) were separated in 6 to 15\% SDS-polyacrylamide gels, 


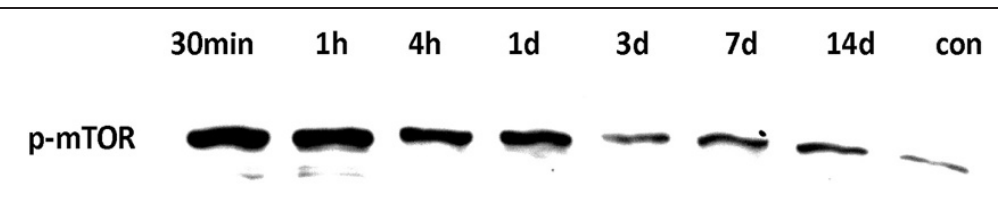

tubulin

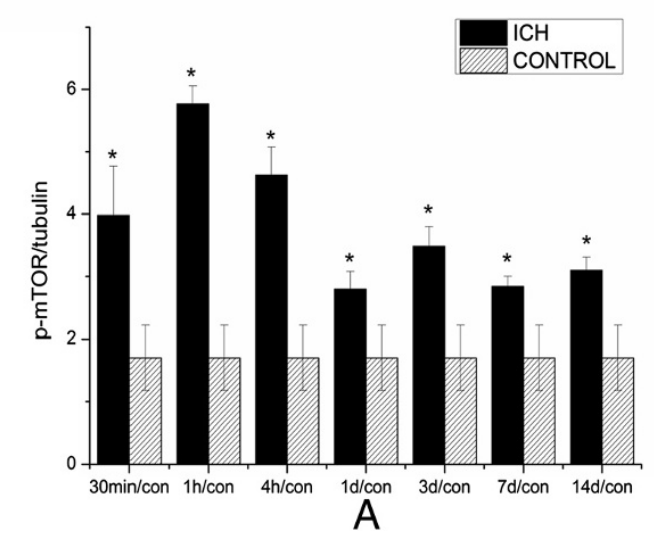

Figure 1 Mammalian target of rapamycin (mTOR) was activated after intracerebral hemorrhage (ICH). (A) Protein from the ipsilateral hemisphere was analyzed by western blotting using anti-p-mTOR (Ser 2448)., which was was greatly increased at 30 minutes after ICH and lasted up to 14 days after ICH. The level of $p$-mTOR was normalized to the level of tubulin. ${ }^{*} P<0.05$.

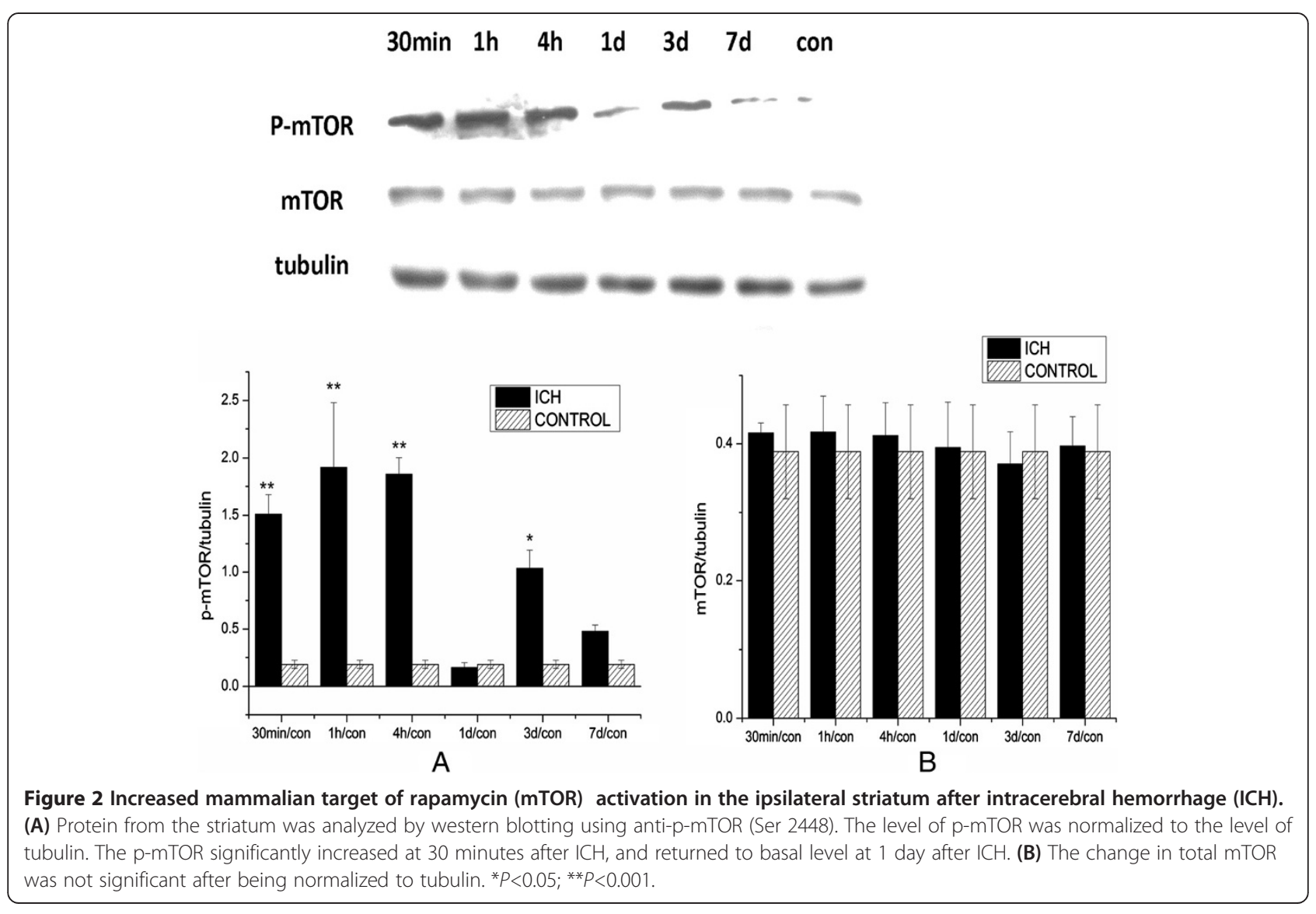


and transferred to PVDF membranes. After blocking, the membranes were incubated overnight at $4^{\circ} \mathrm{C}$ with the following primary antibodies: rabbit anti-mTOR monoclonal antibody, rabbit anti-p-mTOR (Ser 2448) polyclonal antibody, rabbit anti-phospho -p70S6 (Thr 389) monoclonal antibody, rabbit anti-p70S6 monoclonal antibody, rabbit anti-tubulin polyclonal antibody (1:1000) (all from Cell Signaling Technology). After washing three times in TBS buffer with $0.1 \%$ Tween (TBS-T), membranes were further incubated with HRP-conjugated anti-rabbit IgG secondary antibody for $1 \mathrm{~h}$ at room temperature, and the bands were visualized by enhanced chemiluminescence (Thermo, USA) and X-ray film(Thermo, USA) exposure. Quantity One software (BioRad) was used to detect the band intensities. To ensure reproducibility, all experiments were repeated at least three times.

\section{Behavioral testing}

For behavioral testing, rats were assessed before ICH and at $1,3,7$, and 14 days after $\mathrm{ICH}$ by an investigator who was blinded to the experimental groups using a set of modified Neurological Severity Scores (mNSS) [26,27]. The mNSS is a complex behavioral test including motor, sensory, reflex, and balance tests. In this test, the scores ranged from 0 to 18 , where 0 was considered normal and 18 was maximum deficit.

\section{Flow cytometry}

At 3 days after $\mathrm{ICH}$, control rats $(\mathrm{n}=6), \mathrm{ICH}$ rats $(\mathrm{n}=8)$, and rats treated with $150 \mu \mathrm{g} / \mathrm{kg}$ rapamycin $(\mathrm{n}=10)$ were euthanized and perfused with saline. The blood and brain of each rat were collected, and the monocytes were separated as described previously [28]. Cells were stained with antibodies (BD Biosciences): FITC-anti-rat-CD4, APC-anti-rat-CD25, and PE-anti-rat-FoxP3. Stained cells were analyzed by blinded evaluators using a flow cytometer (FACSCalibur; BD Biosciences, USA) and Flowjo 7.6 software.

\section{ELISA}

To test the inflammatory response after rapamycin treatment, colorimetric ELISA kits were used to detect the following cytokines in serum and brain protein extract: rat IL-10, rat interferon (IFN)- $\gamma$, and rat TGF- $\beta$ (all R\&D Systems, USA). For each ELISA analysis, $40 \mu \mathrm{l}$ of sample was used without dilution in accordance with the manufacturer's instructions.

\section{Statistical analysis}

Data areshown as means \pm standard deviation (SD). Statistical differences between normal control group and other groups were compared using student T-tests. Statistical significance was defined as ${ }^{*} P<0.05$ and ${ }^{* *} P<0.001$.

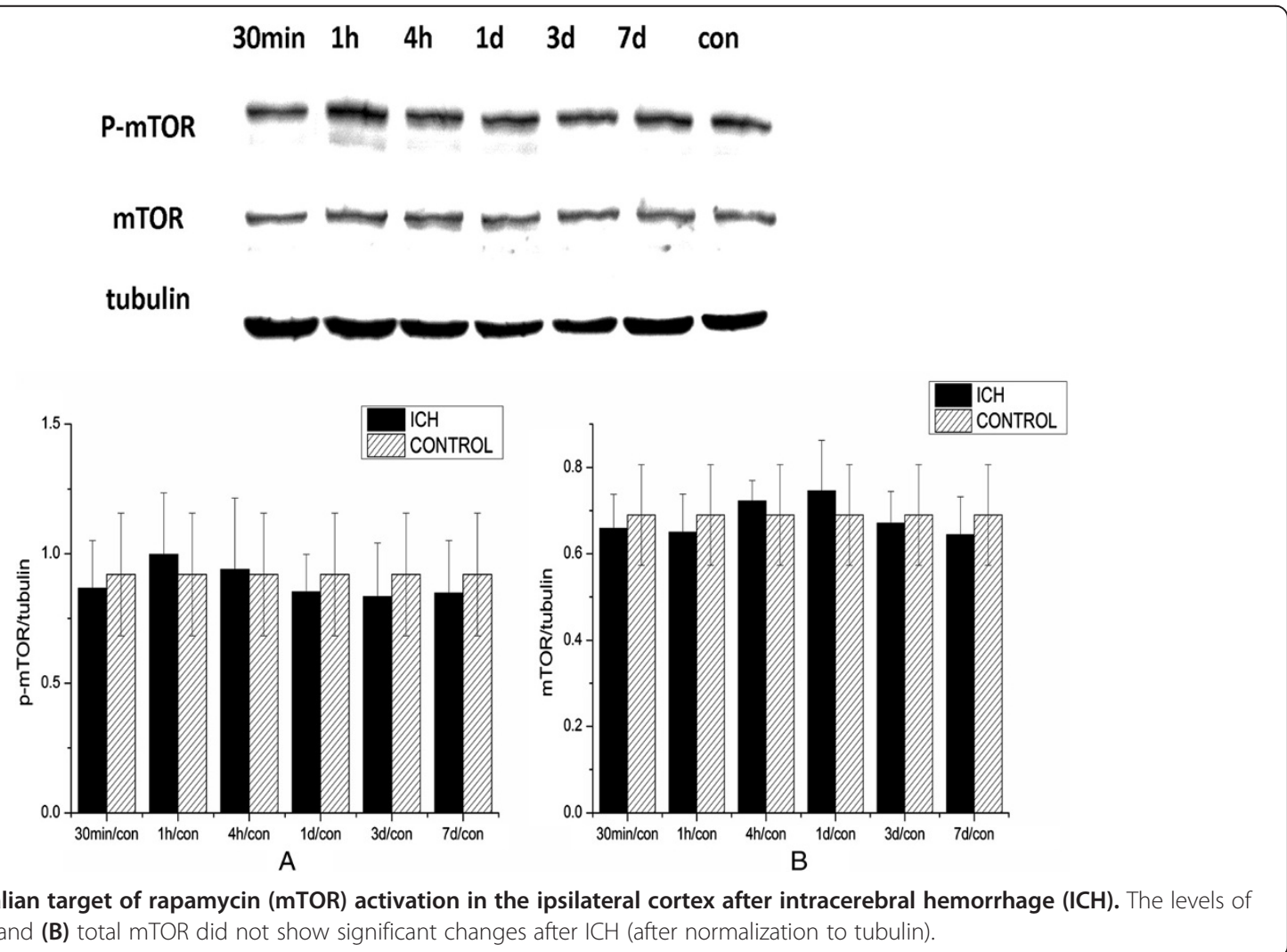




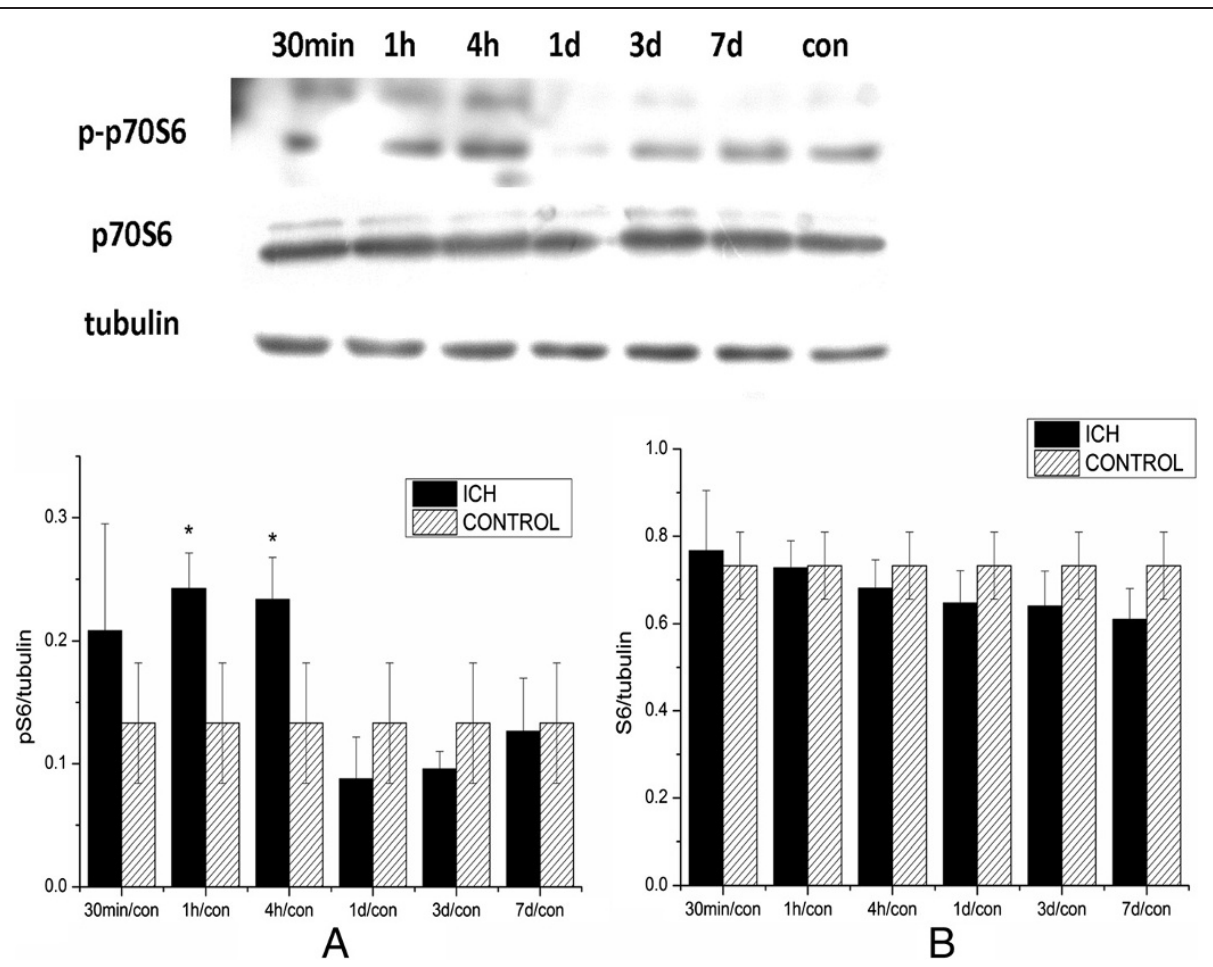

Figure 4 Increased p70S6 activation in the ipsilateral striatum after intracerebral hemorrhage (ICH). (A) Protein from the striatum was analyzed by western blotting using anti-p-p70S6 (Thr 389). The level of p-p70S6 was normalized to the level of tubulin. p-mTOR was significantly increased at 1 hour and returned to basal level at 1 day after $\mathrm{ICH}$. (B) The change in total p70S6 was not significant after being normalized to tubulin. ${ }^{*} P<0.05$.

\section{Results}

\section{Alteration of mTOR signaling pathway after $\mathrm{ICH}$}

To study alterations in the mTOR signaling pathway after $\mathrm{ICH}$, protein lysis samples from the ipsilateral hemisphere were separated by electrophoresis and analyzed by western blotting. We found increased phosphorylation of mTOR in the ipsilateral hemisphere of $\mathrm{ICH}$ rats from 30 minutes to 14 days after ICH (Figure 1), suggesting that activation of mTOR signaling was both rapid and long-lasting after $\mathrm{ICH}$.

To further study the profile of mTOR activation in different regions of the ipsilateral hemisphere, we analyzed the protein from the striatum surrounding the hematoma and cortex (both regions extended $2 \mathrm{~mm}$ around the needle tip) by western blotting. We observed that mTOR phosphorylation in the ipsilateral striatum was significantly increased at 30 minutes, peaked at 1 hour, and returned to basal level about 1 day after ICH (Figure 2). The level of total mTOR was not significantly changed after ICH., and the mTOR activation level in the cortex was not significantly activated after ICH (Figure 3 ).

To detect whether mTOR signaling was also activated following $\mathrm{ICH}$, western blotting was performed using anti-p70 ribosomal S6 kinase (p70S6), one of the main downstream targets of the mTOR signaling [29-31]. Compared with the control group, phosphorylation of p70S6 was also activated at 1 hour after ICH (Figure 4), but the level of total p70S6 was not significantly changed after ICH.

\section{Effect of rapamycin on the neurobehavior of $\mathrm{ICH}$ rats}

To determine the role of mTOR signaling after $\mathrm{ICH}$, rapamycin, an mTOR inhibitor, was injected intraperitoneally at 1 hour after ICH. Neurobehavioral function was evaluated in different groups using the mNSS. Rats were trained 3 days before $\mathrm{ICH}$ to assess the normal level (score $=0$ ). At 1 day after $\mathrm{ICH}$, the mean mNSS values were $9.56 \pm 0.68$ in the $\mathrm{ICH}$ group, $9.50 \pm 0.50$ in the PBS group, $9.00 \pm 0.67$ in the $50 \mu \mathrm{g} / \mathrm{kg}$ rapamycintreated group, $8.00 \pm 0.67$ in the $150 \mu \mathrm{g} / \mathrm{kg}$ rapamycintreated group, and $7.11 \pm 0.74$ in the $250 \mu \mathrm{g} / \mathrm{kg}$ rapamycin-treated group (Figure 5). Statistical analysis showed significant differences between the $\mathrm{ICH}$ group and the rapamycin-treated groups (except the $50 \mu \mathrm{g} / \mathrm{kg}$ group and $500 \mu \mathrm{g} / \mathrm{kg}$ group). Results for neurobehavioral outcomes at 3, 7 and 14 days after $\mathrm{ICH}$ were similar to those given above for 1 day after $\mathrm{ICH}$. There were no significant differences between the $\mathrm{ICH}$ group and the PBS group. These results suggest that rapamycin significantly improved the functional recovery of the $\mathrm{ICH}$ rats in a dose-dependent manner. However, we found that rats treated with the highest concentration of rapamycin $(500 \mu \mathrm{g} / \mathrm{kg})$ were too sick to be evaluated and six 


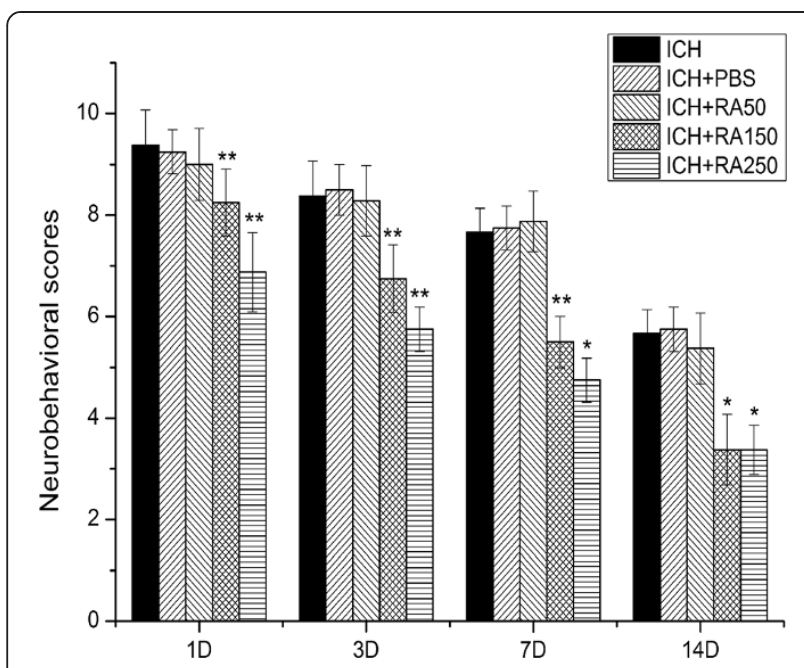

Figure 5 Rapamycin improves recovery of neurobehavioral function after intracerebral hemorrhage (ICH). The scores in both the $\mathrm{ICH}$ and rapamycin groups were similar before $\mathrm{ICH}$. At 1 hour after $\mathrm{ICH}$, rapamycin-treated groups were injected with rapamycin using different concentrations: 50, 150, 250, and $500 \mu \mathrm{g} / \mathrm{kg}$. The behaviors were evaluated and compared at 1, 3, 7, and 14 days after $\mathrm{ICH}$. We observed a significant functional recovery in rapamycin-treated groups compared with the ICH group. The mean modified Neurological Severity Score (mNSS) values \pm SEM are depicted, ${ }^{*} P<0.05 ;{ }^{*} P<0.001$ compared with $\mathrm{ICH}$ rats. of them died after treatment. Considering that there were no significant differences between the $150 \mu \mathrm{g} / \mathrm{kg}$ and the $250 \mu \mathrm{g} / \mathrm{kg}$ groups at each time point, we propose that the best dose of rapamycin for $\mathrm{ICH}$ treatment is $150 \mu \mathrm{g} / \mathrm{kg}$.

\section{Rapamycin improves the neurobehavioral deficits in rats} after ICH by mTOR signaling

In order to assess whether rapamycin improved functional recovery by inhibiting mTOR signaling, rats were euthanized 4 hours after receiving rapamycin (at various concentrations). As shown in Figure 6, rapamycin treatment $(150,250$ and $500 \mu \mathrm{g} / \mathrm{kg}$, but not $50 \mu \mathrm{g} / \mathrm{kg})$ significantly reduced the p-mTOR level in the striatum. Although higher concentrations of rapamycin had a stronger inhibition on p-mTOR, there was no significant difference between the groups treated with 150 and $250 \mu \mathrm{g} / \mathrm{kg}$, further suggesting that $150 \mu \mathrm{g} / \mathrm{kg}$ is the best dose of rapamycin for $\mathrm{ICH}$ treatment.

\section{Rapamycin increases Tregs in the peripheral blood and ipsilateral hemisphere}

In order to evaluate the effects of rapamycin on the immune response of $\mathrm{ICH}$ rats, we separated monocytes from peripheral blood and brain as described previously [28], and analyzed the level of CD4+CD25+Foxp3+ Tregs was analyzed by flow cytometry. The control and

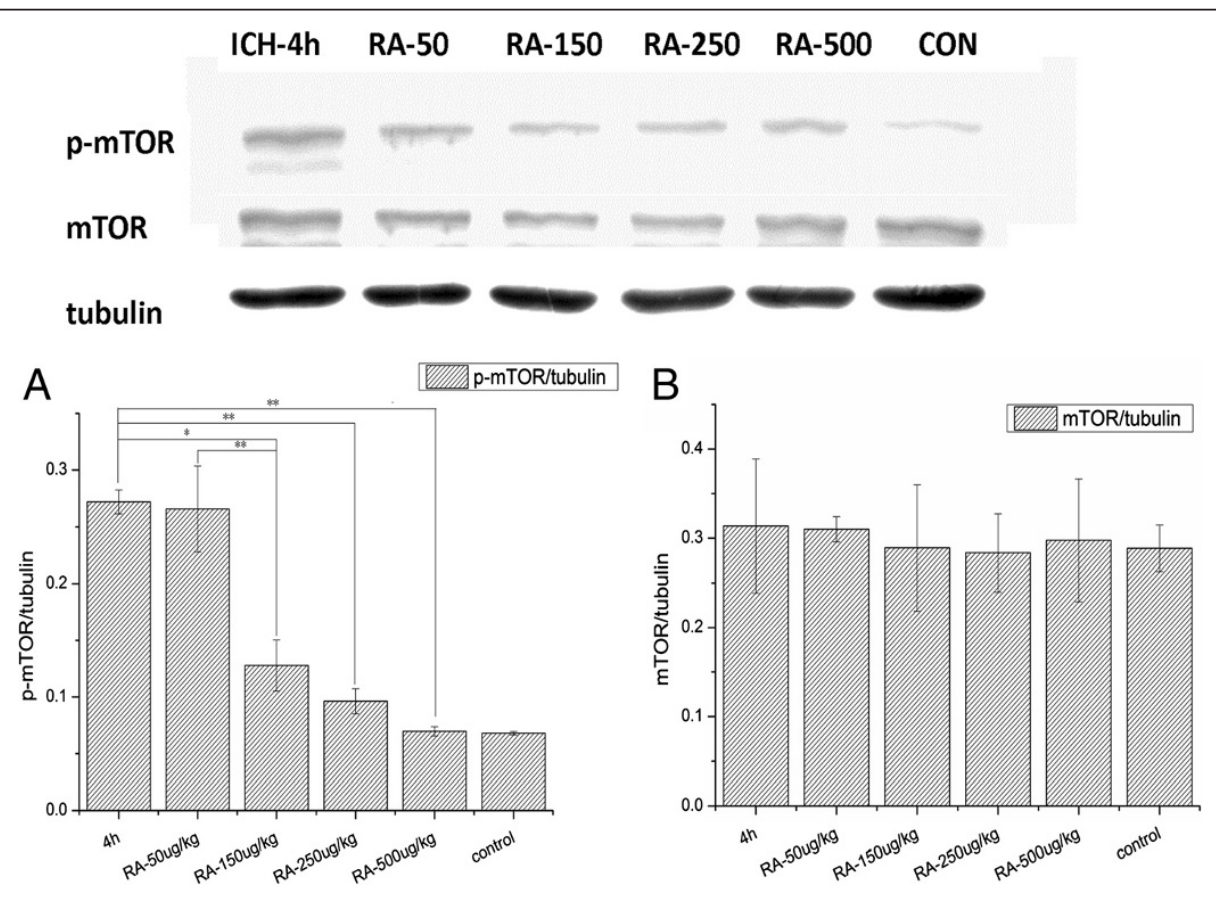

Figure 6 Rapamycin inhibited p-mammalian target of rapamycin (mTOR) in the striatum. (A) Compared with the intracerebral hemorrhage (ICH) group (4 h after ICH), significantly lower levels of p-mTOR were observed in the 150, 250, and $500 \mu \mathrm{g} / \mathrm{kg}$ treated groups while there was no significant change in the $50 \mu \mathrm{g} / \mathrm{kg}$ treated group. (B) The total mTOR level in rapamycin-treated groups was similar to that of the ICH group. Both p-mTOR and total mTOR were normalized to tubulin. ${ }^{*} P<0.05 ;{ }^{*} P<0.001$. 
ICH groups had similar numbers of CD4+Foxp3+ Tregs in the peripheral blood $(0.931 \pm 0.145 \%$ and $1.035 \pm 0.207 \%$, respectively). However, the group treated with $150 \mu \mathrm{g} / \mathrm{kg}$ rapamycin had a significantly higher level of CD4+Foxp3+ Tregs (1.797 \pm 0.434\%) than the other two groups (Figure 7). Similar to the findings for peripheral blood, CD4+Foxp3+ Tregs in the ipsilateral hemisphere (Figure 8) were increased in the group treated with $150 \mu \mathrm{g} / \mathrm{kg}$ rapamycin $(3.103 \pm 0.170 \%)$, and no significant difference was observed between the control $(1.599 \pm 0.031 \%)$ and $\mathrm{ICH}(1.407 \pm 0.179 \%)$ groups. The results indicated that rapamycin could expand CD4+CD25+FoxP3+ Tregs in the peripheral blood and ipsilateral hemisphere.

\section{Effect of rapamycin on cytokines in peripheral blood and ipsilateral hemisphere}

To further study the effect of rapamycin on cytokines after ICH, we examined the level of IFN- $\gamma$ and IL-10 in the peripheral blood and around the intracerebral hematoma by ELISA. As shown in Figures 9 and 10, the level of IFN- $\gamma$ was substantially downregulated both in serum and around the hematoma after treatment with rapamycin (Figures 9A and 10A), whereas the levels of IL-10 and TGF- $\beta$ were upregulated (Figure 9B,D; Figure $10 \mathrm{~B}, \mathrm{D})$. The ratio of IL-10 to IFN- $\gamma$ was significantly higher in rapamycin-treated groups (Figures $9 \mathrm{C}$ and 10C). The increased IL-10 and TGF- $\beta$, and decreased IFN- $\gamma$ levels imply that rapamycin modulates inflammatory response in peripheral blood and brain after $\mathrm{ICH}$.

\section{Effect of rapamycin on immune response in the autologous blood-injection model of ICH}

Considering that collagenase can induce some cerebral inflammation, we explored the effect of rapamycin $(150 \mu \mathrm{g} / \mathrm{kg})$ on immune response in the autologous blood-injection model of $\mathrm{ICH}$. We found that rapamycin also decreased the level of IFN- $\gamma$ and increased
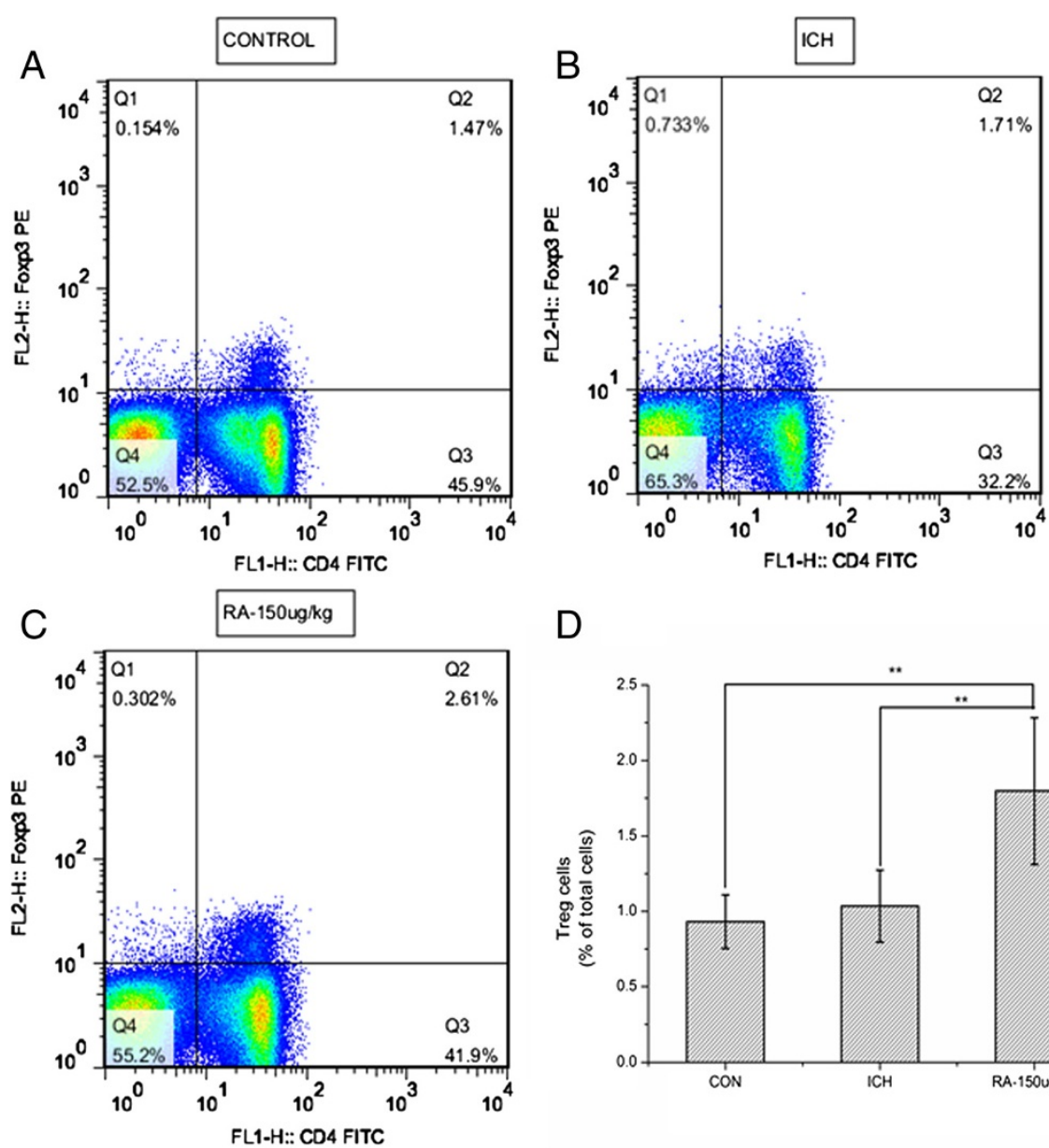

D

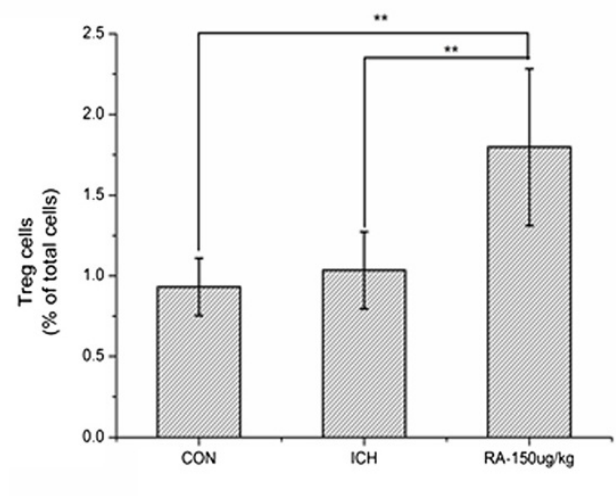

Figure 7 Rapamycin increased the level of regulatory T cells (Tregs) in the blood. Dot plots labeled with CD4 and Foxp3 show the blood lymphocytes derived from (A) control group, (B) intracerebral hemorrhage (ICH) group, and (C) $150 \mu \mathrm{g} / \mathrm{kg}$ rapamycin-treated group. (D) A statistical graph for the three groups. There were significant differences between the control group and rapamycin-treated groups, and between the ICH and rapamycin-treated groups. ${ }^{*} P<0.05$. 

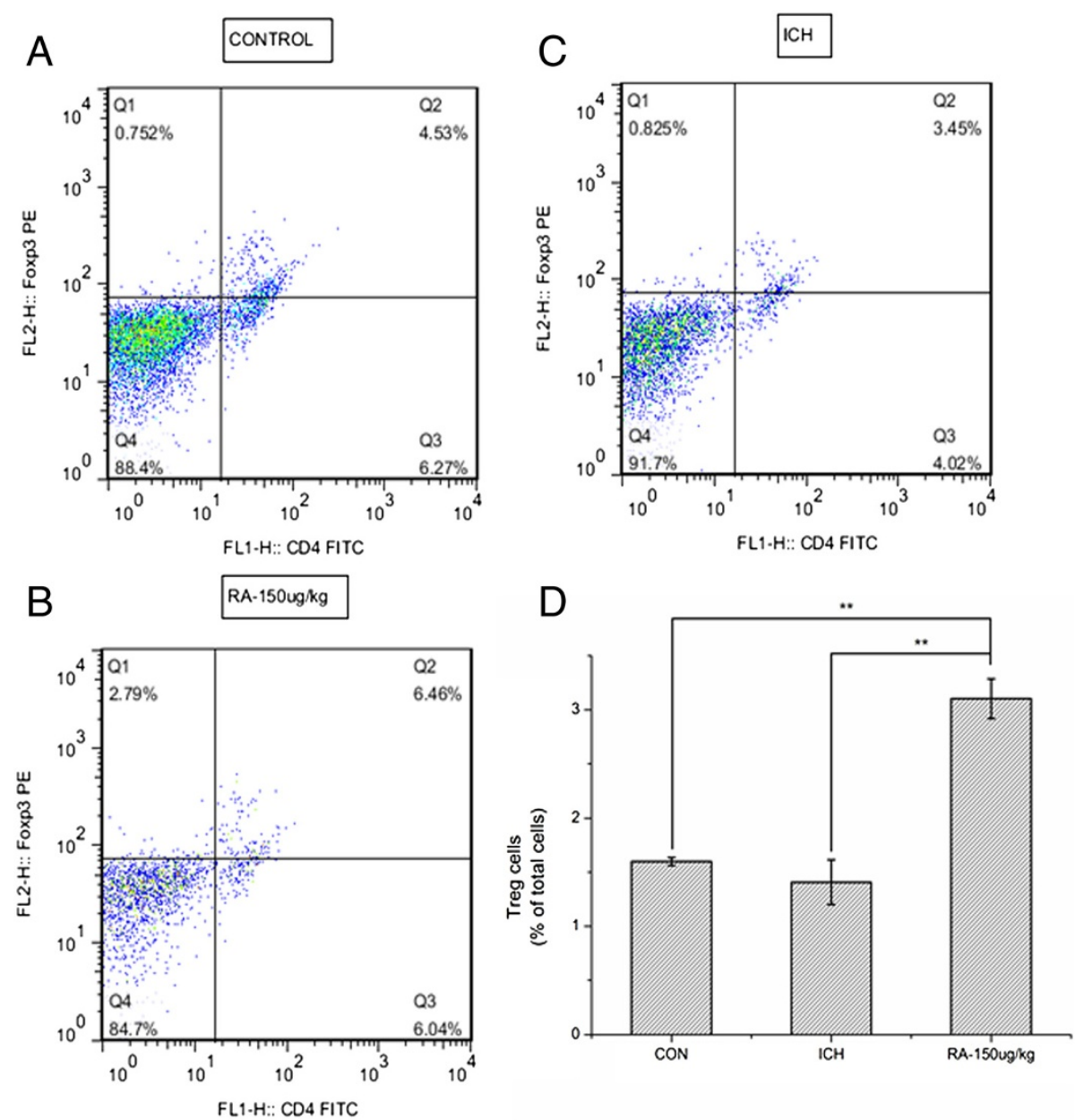

Figure 8 Rapamycin increased the level of regulatory T cells (Tregs) in the ipsilateral hemisphere. Dot plots labeled with CD4 and Foxp3 show the brain lymphocytes from (A) control group, (B) intracerebral hemorrhage (ICH) group, and (C) $150 \mu \mathrm{g} / \mathrm{kg}$ rapamycin-treated group. (D) A statistical graph for the three groups. There were significantly higher levels of Tregs in the rapamycin-treated group than the control and $\mathrm{ICH}$ groups. ${ }^{*} P<0.001$.

the level of IL-10 both in serum and around the hematoma in the autologous blood-injection model (Figure 11). Although the level of IFN- $\gamma$ was higher in the collagenase-injection model than in the autologous bloodinjection model after ICH, there was no significant difference between the two models (Figure 11A,B), suggesting that collagenase could induce inflammation, but did not significantly increase the level of IFN- $\gamma$. These results further suggest the anti-inflammatory effect of rapamycin after $\mathrm{ICH}$.

\section{Discussion}

In the present study, we found evidence that the mTOR signaling was activated 30 minutes after $\mathrm{ICH}$, and returned to its basal level 1 day after $\mathrm{ICH}$. The increased p-mTOR was predominantly located around the hematoma. Rapamycin treatment significantly improved the neurobehavioral deficit after $\mathrm{ICH}$, and increased the number of Tregs, along with the levels of IL-10 and TGF- $\beta$, and reduced the level IFN- $\gamma$ both in peripheral blood and brain. Our study suggests that mTOR improves ICH outcome and modulates immune response after $\mathrm{ICH}$.

mTOR plays a crucial role in regulating many activities, including protein synthesis, cell growth, and cell death. Accumulating evidence indicates that mTOR is dysregulated in various brain diseases, and inhibition of mTOR by rapamycin provides neuroprotective effects. In a mouse model of tuberous sclerosis complex, Zeng et al. found that mTOR signaling is widespread and is stimulated by acute seizure activity, and that rapamycin treatment could reduce mossy fiber sprouting and epilepsy [10]. In a TBI model, Chen et al. found that mTOR was significantly activated from 30 minutes to 24 hours and may contribute to the deficits in learning and memory after TBI [14], while Erlich et al. demonstrated 

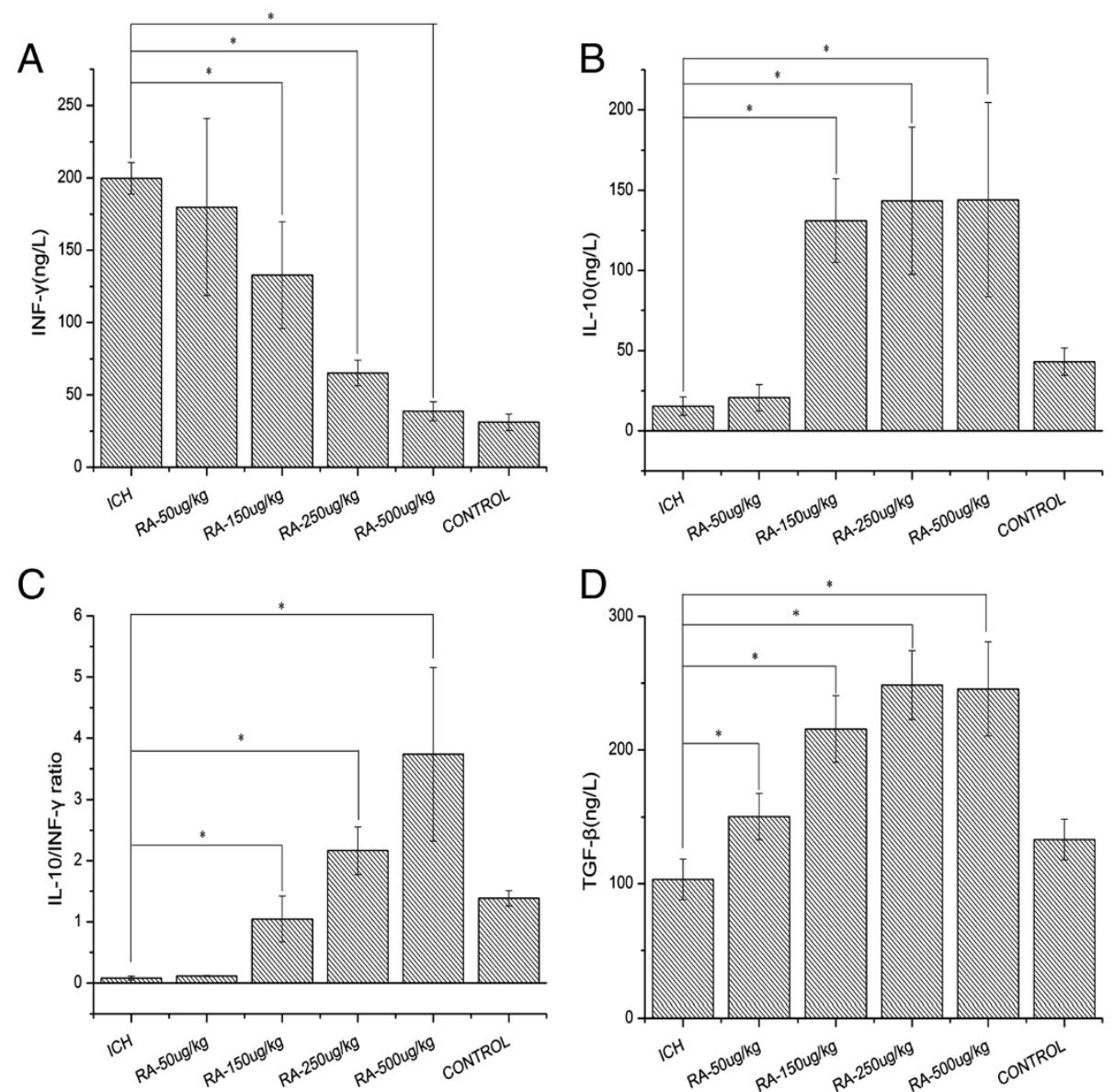

Figure 9 Levels of cytokines in the serum after rapamycin treatment. (A) The levels of interferon (IFN)- $\gamma$ in each rapamycin-treated group were lower than the intracerebral hemorrhage (ICH) group. (B) Rapamycin-treated groups presented higher interleukin (IL)-10 expression than the ICH group. (C) The ratio of interleukin (IL)-10 to IFN- $\gamma$ increased after treatment with rapamycin (150, 250, and $500 \mu \mathrm{gg} / \mathrm{kg}$, but not $50 \mu \mathrm{gg} / \mathrm{kg}$ ). (D) Rapamycin increased the level of transforming growth factor (TGF)- $\beta$. There were no significant differences between the 150, 250, and $500 \mathrm{\mu g} / \mathrm{kg}$ rapamycin-treated groups. ${ }^{*} P<0.05$.

that rapamycin injection administered 4 hours following TBI reduced microglial activation and increased the number of surviving neurons at the site of injury to improve functional recovery [32]. In a model of neonatal hypoxia-ischemia, Carloni et al. showed that rapamycin increased autophagy, reduced necrotic cell death, and decreased brain injury [33]. In a dog model of subarachnoid hemorrhage (SAH), Zhang et al. found that mTOR signaling was activated in vascular smooth muscle cells, which contributed to cerebral vasospasm following SAH injury, and that rapamycin could inhibit mTOR signaling and attenuate angiographic vasospasm [34]. Consistently, our study indicated that mTOR was upregulated after $\mathrm{ICH}$, and the outcome was significantly improved through inhibition of mTOR by rapamycin. Our data suggest that mTOR may be a potential therapeutic target for $\mathrm{ICH}$.
mTOR plays a key role in the inflammatory and immune responses [35], which can sense and integrate cues from the microenvironment to control activation and development of immune cells, including $\mathrm{T}$ cells and microglia. Microglia, innate immune cells residing in the CNS, contribute to initiation and maintenance of cerebral inflammation, release pro-inflammatory mediators that are potentially cytotoxic, and exert detrimental effects when activated permanently [36]. Cinzia et al. showed that mTOR selectively controls microglial activation in response to pro-inflammatory cytokines, and appears to play a crucial role in microglial viability [37]. In our study, mTOR was increased around the hematoma, which may relate to the activation of microglia and release of proinflammatory cytokines. Injection of rapamycin at different concentrations (including 150, 250, and $500 \mu \mathrm{g} / \mathrm{kg}$ ) significantly decreased the level of IFN- $\gamma$ and increased 

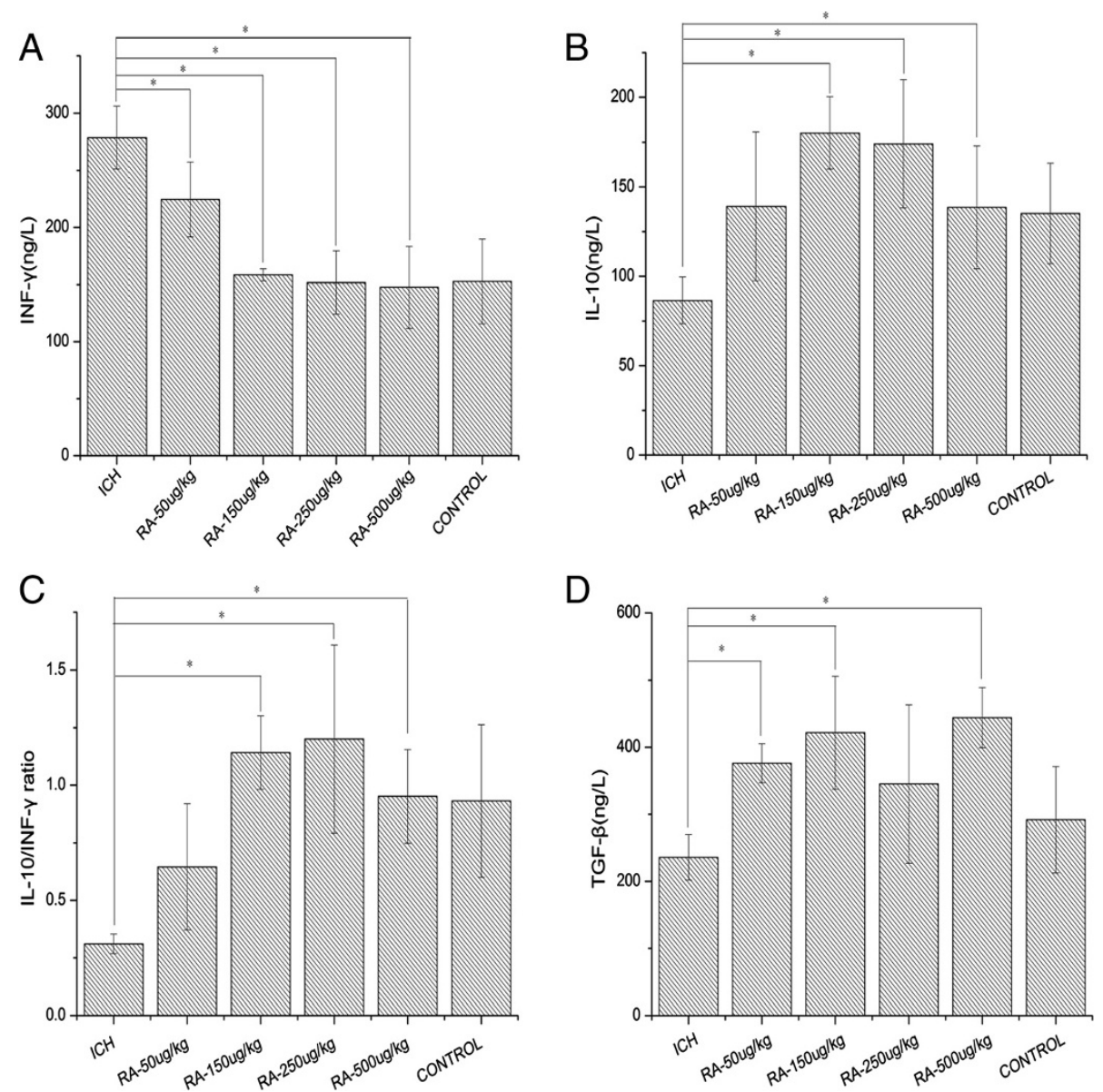

Figure 10 Levels of cytokines around the hematoma after rapamycin treatment. (A) Compared with the intracerebral hemorrhage (ICH) group, the levels of interferon (IFN)- $\gamma$ were reduced in the rapamycin-treated groups except for the $50 \mathrm{\mu g} / \mathrm{kg}$ group. (B) Rapamycin-treated groups had higher levels of interleukin (IL)-10 than the ICH group, except for the $50 \mu \mathrm{g} / \mathrm{kg}$ group. (C) The ratio of IL-10 to IFN- $\gamma$ was increased after treatment with rapamycin $(150,250$, and $500 \mu \mathrm{g} / \mathrm{kg}$, but not $50 \mu \mathrm{g} / \mathrm{kg}$ ). (D) Rapamycin increased the level of transforming growth factor (TGF)- $\beta$. ${ }^{*} P<0.05$.

the levels of IL-10 and TGF- $\beta$ both in the hematoma and in serum.

IFN- $\gamma$ is a key regulator of immune and inflammatory responses. In various neural diseases, IFN- $\gamma$ is produced by infiltrating $T$ cells, and is associated with onset and process of pathology [38]. IFN- $\gamma$ was shown to induce the expression of TNF, IL-1 $\beta$, nitric oxide synthase, and oxygen synthase $[39,40]$, all of which could aggravate the neural disabilities after ICH. By contrast, IL-10, an anti-inflammatory cytokine, was shown to limit inflammation in the brain by reducing the synthesis of pro-inflammatory cytokines, and suppressing expression and activation of the cytokine receptor [41]. In addition, Sharma et al. found that IL-10 increased neuronal survival after exposure to oxygen-glucose deprivation by inducing phosphorylation of pro-survival pathways such as AKT and STAT-3 signaling in vitro [42]. Thus, by upregulating IL-10 and downregulating IFN- $\gamma 4$ hours after $\mathrm{ICH}$, rapamycin plays an anti-inflammatory role in the peripheral blood and brain at an early stage, which could decrease brain damage and contribute to neural recovery.

At the same time, TGF- $\beta$ is a pleiotropic cytokine with a central role in inflammation. In a murine stroke model, injection of TGF- $\beta 1$ into the lesion border zone greatly reduced infarct bleeding by recruiting bone marrow-derived monocytes/macrophages, which are important for maintaining integrity of the neurovascular unit following brain ischemia [43]. In humans with stroke, levels of TGF- $\beta 1$ were found to be increased in the ischemic penumbra, which is essential for angiogenesis after stroke [44]. Abundant studies have shown that TGF- $\beta$ can induce angiogenesis and neurogenesis following stroke [45-47]. Considering the role of TGF- $\beta$ in angiogenesis and neurogenesis, rapamycin may promote functional recovery after $\mathrm{ICH}$ by increasing the levels of TGF- $\beta$ in the blood and brain, as shown by our study. 


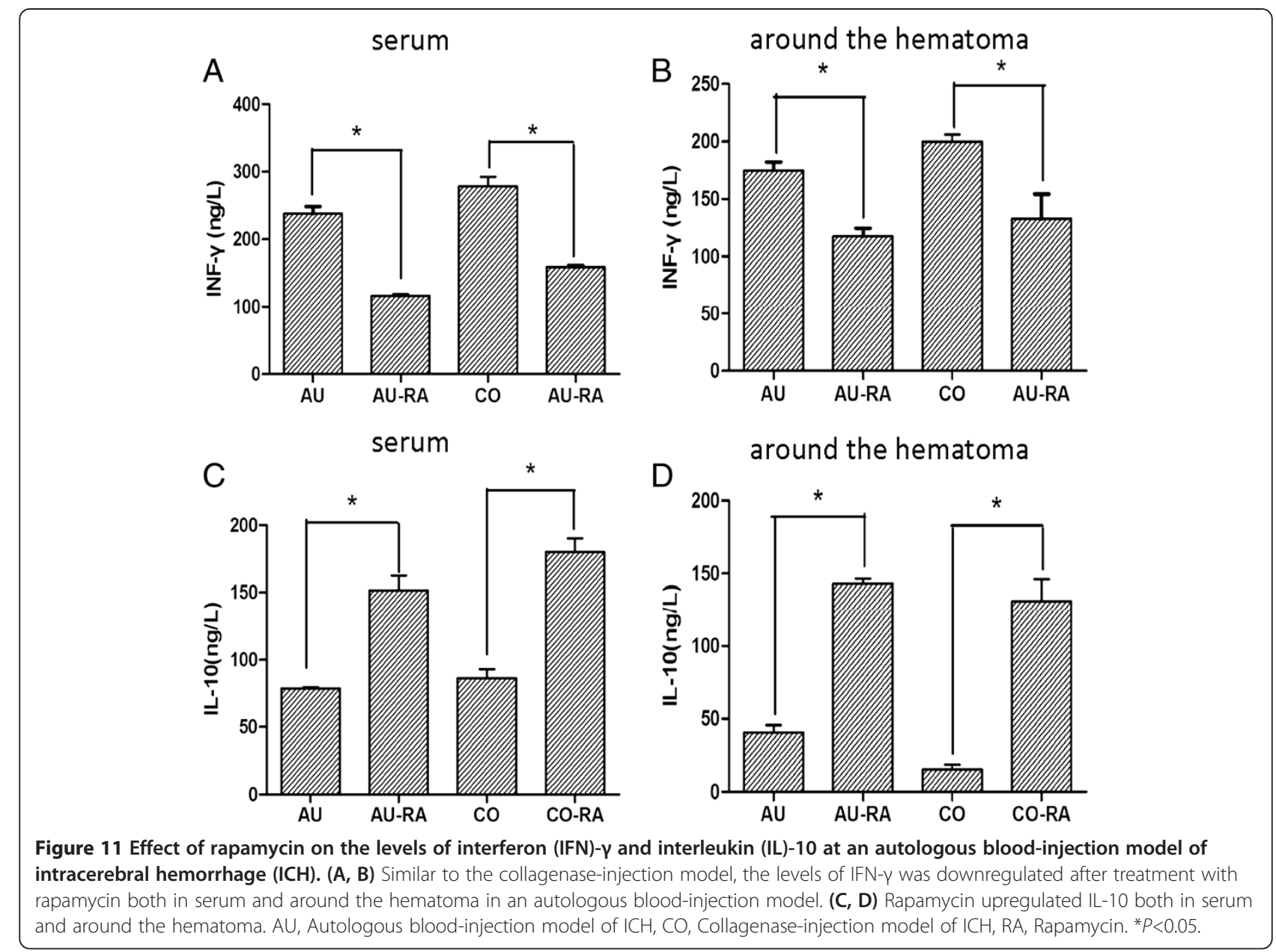

Naive CD4+ T cells, when stimulated by antigen, proliferate and differentiate to T helper type 1 (Th1) cells, Th2 cells and Th17 cells, which favor the generation of Tregs $[48,49]$. In a model of acute experimental stroke, Liesz et al. found that depletion of Tregs profoundly delayed brain damage and deteriorated functional outcome after injection of anti-CD25 antibody. They concluded that Tregs were major cerebroprotective modulators of postischemic inflammatory brain damage through IL-10 signaling [19]. In the present study, we found that Tregs were significantly increased in peripheral blood and ipsilateral hemisphere at 3 days after rapamycin injection. Taken together, these results show that the increased Treg numbers and altered cytokines may be associated with improved outcome after repamycin treatment.

\section{Conclusion}

Our study provides the first evidence that the mTOR signaling pathway is abnormally activated in brain after $\mathrm{ICH}$, especially around the hematoma. Secondly, rapamycin treatment given 1 hour after $\mathrm{ICH}$ can promote neurologic functional recovery. Lastly, the underlying mechanisms may be the effect of rapamycin in regulating inflammatory and immune responses, including upregulation of IL-10, TGF- $\beta$, and Tregs, and downregulation of IFN- $\gamma$. Therefore, mTOR may be a novel therapeutic target for $\mathrm{ICH}$.

\section{Abbreviations}

APC: Allophycocyanin; CNS: Central nervous system; FITC: fluorescein isothiocyanate; HRP: horseradish peroxidase; ICH: Intracerebral hemorrhage; IFN: interferon; IL: Interleukin; mTOR: Mammalian target of rapamycin; PE: Phycoerythrin; PVDF: Polyvinylidene fluoride; SAH: Subarachnoid hemorrhage; TBI: Traumatic brain injury; TGF: Transforming growth factor.

\section{Competing interests}

The authors confirm that there are no conflicts of interests.

\section{Authors' contributions}

QL designed and performed the study, analyzed data, and wrote the manuscript. LG, WLH, JJY, ZXL, and YLZ performed the study and analyzed data. $L H$ and LHR helped to analyze data. KLJ helped to design study and write the manuscript, QCZG designed the study and obtained funding for the study. All authors read and approved the final manuscript. 


\section{Acknowledgements}

The study was supported by a grant from the National Natural Science foundation of China (No. 81171088). We are grateful to Professor Dong-Ming Su (University of North Texas Health Science Center, USA) for critical suggestions on the experiments.

\section{Author details}

'Department of Neurosurgery, First Affiliated Hospital of Wenzhou Medical University, Wenzhou, Zhejiang, China. ${ }^{2}$ Zhejiang Provincial Key Laboratory of Aging and Neurological Disease, Wenzhou Medical University, Wenzhou, Zhejiang, China. ${ }^{3}$ Department of Pharmacology and Neuroscience, Institute for Aging and Alzheimer's Disease Research, University of North Texas Health Science Center at Fort Worth, Fort Worth, TX, USA.

Received: 28 September 2013 Accepted: 21 February 2014 Published: 6 March 2014

\section{References}

1. Ingall T: Stroke-incidence, mortality, morbidity and risk. J Insur Med 2004 36:143-152.

2. Qureshi Al, Tuhrim S, Broderick JP, Batjer HH, Hondo H, Hanley DF: Spontaneous intracerebral hemorrhage. N Engl J Med 2001, 344:1450-1460.

3. Inagawa $\mathrm{T}$ : What are the actual incidence and mortality rates of intracerebral hemorrhage? Neurosurg Rev 2002, 25:237-246.

4. Kunz J, Henriquez R, Schneider U, Deuter-Reinhard M, Movva NR Hall MN: Target of rapamycin in yeast, TOR2, is an essential phosphatidylinositol kinase homolog required for $\mathrm{G} 1$ progression. Cell 1993, 73:585-596.

5. Brown EJ, Albers MW, Shin TB, Ichikawa K, Keith CT, Lane WS, Schreiber SL: A mammalian protein targeted by G1-arresting rapamycin-receptor complex. Nature 1994, 369:756-758.

6. Sabatini DM, Erdjument-Bromage H, Lui M, Tempst P, Snyder SH: RAFT1: a mammalian protein that binds to FKBP12 in a rapamycin-dependent fashion and is homologous to yeast TORs. Cell 1994, 78:35-43.

7. Castilho RM, Squarize CH, Chodosh LA, Williams BO, Gutkind JS: mTOR mediates Wnt-induced epidermal stem cell exhaustion and aging Cell Stem Cell 2009, 5:279-289.

8. Harris TE, Lawrence JC Jr: TOR signaling. SCi STKE 2003, 212:re15.

9. Inoki K, Zhu T, Guan KL: TSC2 mediates cellular energy response to control cell growth and survival. Cell 2003, 115:577-590.

10. Zeng LH, Rensing NR, Wong M: The mammalian target of rapamycin signaling pathway mediates epileptogenesis in a model of temporal lobe epilepsy. J Neurosci 2009, 29:6964-6972.

11. Pan T, Kondo S, Zhu W, Xie W, Jankovic J, Le W: Neuroprotection of rapamycin in lactacystin-induced neurodegeneration via autophagy enhancement. Neurobiol Dis 2008, 32:16-25.

12. Malagelada C, Jin ZH, Jackson-Lewis V, Przedborski S, Greene LA: Rapamycin protects against neuron death in in vitro and in vivo models of Parkinson's disease. J Neurosci 2010, 30:1166-1175.

13. An WL, Cowburn RF, Li L, Braak H, Alafuzoff I, lqbal K, Iqbal IG, Winblad B, Pei JJ: Up-regulation of phosphorylated/activated p70 S6 kinase and its relationship to neurofibrillary pathology in Alzheimer's disease. Am J Pathol 2003, 163:591-607.

14. Chen S, Atkins CM, Liu CL, Alonso OF, Dietrich WD, Hu BR: Alterations in mammalian target of rapamycin signaling pathways after traumatic brain injury. J Cereb Blood Flow Metab 2007, 27:939-949.

15. Xi G, Keep RF, Hoff JT: Mechanisms of brain injury after intracerebral haemorrhage. Lancet Neurol 2006, 5:53-63.

16. Wang J, Tsirka SE: Contribution of extracellular proteolysis and microglia to intracerebral hemorrhage. Neurocrit Care 2005, 3:77-85

17. Wang $\mathrm{Q}$, Tang $\mathrm{XN}$, Yenari MA: The inflammatory response in stroke. J Neuroimmunol 2007, 184:53-68.

18. Nilupul Perera M, Ma HK, Arakawa S, Howells DW, Markus R, Rowe CC, Donnan GA: Inflammation following stroke. J Clin Neurosci 2006, 13:1-8.

19. Liesz A, Suri-Payer E, Veltkamp C, Doerr H, Sommer C, Rivest S, Giese T, Veltkamp R: Regulatory T cells are key cerebroprotective immunomodulators in acute experimental stroke. Nat Med 2009, 15:192-199.

20. Suri-Payer $E$, Fritzsching B: Regulatory $T$ cells in experimental autoimmune disease. Springer Semin Immunopathol 2006, 28:3-16.

21. O'Garra A, Vieira P: Regulatory T cells and mechanisms of immune system control. Nat Med 2004, 10:801-805.
22. Battaglia M, Stabilini A, Roncarolo MG: Rapamycin selectively expands CD4 + CD25 + FoxP3+ regulatory T cells. Blood 2005, 105:4743-4748.

23. Kopf H, de la Rosa GM, Howard OM, Chen X: Rapamycin inhibits differentiation of Th17 cells and promotes generation of FoxP3+ T regulatory cells. Int Immunopharmacol 2007, 7:1819-1824.

24. Rosenberg GA, Mun-Bryce S, Wesley M, Kornfeld M: Collagenase-induced intracerebral hemorrhage in rats. Stroke 1990, 21:801-807.

25. Deinsberger W, Vogel J, Kuschinsky W, Auer LM, Boker DK: Experimental intracerebral hemorrhage: description of a double injection model in rats. Neurol Res 1996, 18:475-477.

26. Schallert T, Kozlowski DA, Humm JL, Cocke RR: Use-dependent structural events in recovery of function. Adv Neurol 1997, 73:229-238.

27. Shohami E, Novikov M, Bass R: Long-term effect of HU-211, a novel non-competitive NMDA antagonist, on motor and memory functions after closed head injury in the rat. Brain Res 1995, 674:55-62.

28. Gelderblom M, Leypoldt F, Steinbach K, Behrens D, Choe CU, Siler DA Arumugam TV, Orthey E, Gerloff C, Tolosa E, Magnus T: Temporal and spatial dynamics of cerebral immune cell accumulation in stroke. Stroke 2009, 40:1849-1857.

29. Ma XM, Blenis J: Molecular mechanisms of mTOR-mediated translational control. Nat Rev Mol Cell Biol 2009 , 10:307-318.

30. Radimerski T, Montagne J, Rintelen F, Stocker H, van der Kaay J, Downes CP, Hafen E, Thomas G: dS6K-regulated cell growth is $\mathrm{dPKB} / \mathrm{dPI}(3) \mathrm{K}$-independent, but requires dPDK1. Nat Cell Biol 2002, 4:251-255.

31. Meyuhas O: Synthesis of the translational apparatus is regulated at the translational level. Eur J Biochem 2000, 267:6321-6330.

32. Erlich S, Alexandrovich A, Shohami E, Pinkas-Kramarski R: Rapamycin is a neuroprotective treatment for traumatic brain injury. Neurobiol Dis 2007 26:86-93.

33. Carloni S, Buonocore G, Balduini W: Protective role of autophagy in neonatal hypoxia-ischemia induced brain injury. Neurobiol Dis 2008 32:329-339.

34. Zhang W, Khatibi NH, Yamaguchi-Okada M, Yan J, Chen C, Hu Q, Meng H, Han H, Liu S, Zhou C: Mammalian target of rapamycin (mTOR) inhibition reduces cerebral vasospasm following a subarachnoid hemorrhage injury in canines. Exp Neurol 2012, 233:799-806.

35. Powell JD, Pollizzi KN, Heikamp EB, Horton MR: Regulation of immune responses by mTOR. Annu Rev Immunol 2012, 30:39-68.

36. Wang J, Dore S: Inflammation after intracerebral hemorrhage. J Cereb Blood Flow Metab 2007, 27:894-908.

37. Dello Russo C, Lisi L, Tringali G, Navarra P: Involvement of mTOR kinase in cytokine-dependent microglial activation and cell proliferation. Biochem Pharmacol 2009, 78:1242-1251.

38. Popko B, Corbin JG, Baerwald KD, Dupree J, Garcia AM: The effects of interferon-gamma on the central nervous system. Mol Neurobiol 1997 14:19-35.

39. Meda L, Cassatella MA, Szendrei Gl, Otvos L Jr, Baron P, Villalba M, Ferrari D, Rossi F: Activation of microglial cells by beta-amyloid protein and interferon-gamma. Nature 1995, 374:647-650.

40. Hartlage-Rubsamen M, Lemke R, Schliebs R: Interleukin-1beta, inducible nitric oxide synthase, and nuclear factor-kappaB are induced in morphologically distinct microglia after rat hippocampal lipopolysaccharide/ interferon-gamma injection. J Neurosci Res 1999, 57:388-398,

41. Strle K, Zhou JH, Shen WH, Broussard SR, Johnson RW, Freund GG, Dantzer R, Kelley KW: Interleukin-10 in the brain. Crit Rev Immuno 2001, 21:427-449.

42. Sharma S, Yang B, Xi X, Grotta JC, Aronowski J, Savitz SI: IL-10 directly protects cortical neurons by activating PI-3 kinase and STAT-3 pathways. Brain Res 2011, 1373:189-194

43. Gliem M, Mausberg AK, Lee Jl, Simiantonakis I, van Rooijen N, Hartung HP, Jander S: Macrophages prevent hemorrhagic infarct transformation in murine stroke models. Ann Neurol 2012, 71:743-752.

44. Krupinski J, Kumar P, Kumar S, Kaluza J: Increased expression of TGF-beta 1 in brain tissue after ischemic stroke in humans. Stroke 1996, 27:852-857.

45. Leker RR, Toth ZE, Shahar T, Cassiani-Ingoni R, Szalayova I, Key S, Bratincsak A Mezey E: Transforming growth factor alpha induces angiogenesis and neurogenesis following stroke. Neuroscience 2009, 163:233-243.

46. Krupinski J, Issa R, Bujny T, Slevin M, Kumar P, Kumar S, Kaluza J: A putative role for platelet-derived growth factor in angiogenesis and neuroprotection after ischemic stroke in humans. Stroke 1997, 28:564-573. 
47. Gaengel K, Genove G, Armulik A, Betsholtz C: Endothelial-mural cell signaling in vascular development and angiogenesis. Arterioscler Thromb Vasc Biol 2009, 29:630-638.

48. Zhou L, Chong MM, Littman DR: Plasticity of CD4+ T cell lineage differentiation. Immunity 2009, 30:646-655.

49. Josefowicz SZ, Rudensky A: Control of regulatory T cell lineage commitment and maintenance. Immunity 2009, 30:616-625.

doi:10.1186/1742-2094-11-44

Cite this article as: Lu et al:: Inhibition of mammalian target of rapamycin improves neurobehavioral deficit and modulates immune response after intracerebral hemorrhage in rat. Journal of Neuroinflammation 2014 11:44.

\section{Submit your next manuscript to BioMed Central and take full advantage of:}

- Convenient online submission

- Thorough peer review

- No space constraints or color figure charges

- Immediate publication on acceptance

- Inclusion in PubMed, CAS, Scopus and Google Scholar

- Research which is freely available for redistribution 